\title{
The global approach to rehabilitation following an osteoporotic fragility fracture: A review of the rehabilitation working group of the International Osteoporosis Foundation (IOF) committee of scientific advisors
}

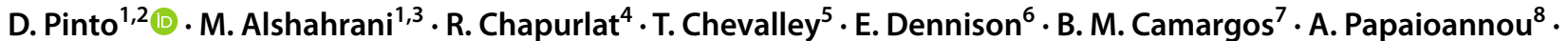 \\ S. Silverman ${ }^{9} \cdot$ J.-F. Kaux ${ }^{10} \cdot$ N. E. Lane ${ }^{11} \cdot$ J. Morales Torres ${ }^{12} \cdot$ J. Paccou $^{13} \cdot$ R. Rizzoli $^{5} \cdot$ O. Bruyere $^{2} \cdot$ on behalf of the $^{1}$ \\ Rehabilitation Working Group of IOF Committee of Scientific Advisors
}

Received: 16 June 2021 / Accepted: 11 November 2021 / Published online: 20 January 2022

(c) International Osteoporosis Foundation and National Osteoporosis Foundation 2021

\begin{abstract}
Purpose To conduct a review of the current state of the evidence for rehabilitation strategies post-fragility fracture. Methods Narrative review conducted by the Rehabilitation Working Group of the International Osteoporosis Foundation Committee of Scientific Advisors characterizing the range of rehabilitation modalities instrumental for the management of fragility fractures.

Results Multi-modal exercise post-fragility fracture to the spine and hip is strongly recommended to reduce pain, improve physical function, and improve quality of life. Outpatient physiotherapy post-hip fracture has a stronger evidence base than outpatient physiotherapy post-vertebral fracture. Appropriate nutritional care after fragility fracture provides a large range of improvement in morbidity and mortality. Education increases understanding of osteoporosis which in turn increases utilization of other rehabilitation services. Education may improve other health outcomes such as pain and increase a patient's ability for self-advocacy.

Conclusion Rehabilitation interventions are inter-reliant, and research investigating the interaction of exercise, nutrition, and other multi-modal therapies may increase the relevance of rehabilitation research to clinical care.
\end{abstract}

Keywords Education $\cdot$ Exercise $\cdot$ Fracture $\cdot$ Nutrition $\cdot$ Osteoporosis $\cdot$ Rehabilitation

D. Pinto

d.pinto@marquette.edu

1 Department of Physical Therapy, Marquette University, P.O. Box 1881, Wisconsin 53201 Milwaukee, USA

2 Department of Public Health, Epidemiology and Health Economics, WHO Collaborating Centre for Public Health Aspects of Musculo-Skeletal Health and Ageing, University of Liège, 4000 Liège, Belgium

3 Department of Medical Rehabilitation Science, King Khalid University, Abha, Kingdom of Saudi Arabia

4 INSERM UMR 1033, Université de Lyon, Hôpital Edouard Herriot, Lyon, France

5 Division of Bone Diseases, Department of Medicine, University Hospitals and Faculty of Medicine of Geneva, Geneva, Switzerland

6 MRC Lifecourse Epidemiology Unit, University of Southampton, Southampton, UK
7 Densitometry Diagnostic Unit - Rede Materdei de Saúde, Belo Horizonte, Mina Gerais, Brazil

8 Department of Medicine, Division of Geriatrics, McMaster University, Hamilton, Canada

9 Cedars-Sinai Medical Center and University of California, Los Angeles, CA, USA

10 Department of Physical and Rehabilitation Medicine, University Hospital of Liège, University of Liège, Liège, Belgium

11 Department of Medicine and Rheumatology, Davis School of Medicine, University of California, Sacramento, CA, USA

12 University of Guanajuato at León, Osteoporosis Unit, Hospital Aranda de La Parra, León, Mexico

13 Département Universitaire de Rhumatologie, Centre Hospitalier Et Universitaire, Hôpital Roger Salengro, Lille, France 


\section{Introduction}

Osteoporosis is characterized by low bone mineral density and changes in bone structure resulting in an increased risk of fracture [1]. Approximately $30 \%$ of all postmenopausal women are reported to have osteoporosis. Of these, $40 \%$ will have an osteoporotic fracture, also known as 'fragility fracture' or low-energy fracture [2]. At the age of 50, lifetime risk of fracture is 40 to $50 \%$ for women; i.e., 1 out of 2 women is at risk of experiencing a fracture during her remaining life time [3], whereas 1 out of 5 men will experience a fragility fracture [4]. Fragility fractures result from mechanical forces that would not ordinarily result in fracture; the amount of force is commonly described as equivalent to a fall from a standing height or less [3]. Fractures associated with osteoporosis occur most often in the hip, wrist, proximal humerus, or vertebrae, with worldwide annual estimates of 9 million fragility fractures [2]. Due to the high incidence, the economic impact worldwide is substantial with estimates of treatment costs at $\$ 17 \mathrm{Bil}-$ lion (2005 USD) per annum in the US [5] and $€ 37$ Billion (2010 Euro) [6]. With the global growth of the elderly population, the economic burden is estimated to increase.

Fragility fractures are associated with pain, loss of bone mineral density (BMD) and muscle mass, disability, reduced quality of life, increased risk of subsequent fracture, and death. Nearly $40 \%$ of individuals who fracture their hip will be institutionalized or unable to walk independently within the year, $60 \%$ will require assistance a year later [7], and approximately one in four will die within a year [8]. Twenty percent of women who have a vertebral fracture will have another within a year, and the risk of death of those with a vertebral fracture is 2.7 times higher than those without [9]. Within the first year of a fragility fracture at any location, the risk of a future fracture is greater than double the risk for matched controls, and the risk remains higher for 10 years [10].

Guidance for the prevention, management, and treatment of osteoporosis has been developed by multiple national and regional organizations, and international campaigns exist to reduce the morbidity and mortality associated with osteoporosis [3]. The treatment of individuals post-fracture is multi-factorial. Pharmaceutical agents are often considered the first line of treatment for osteoporosis because future fractures can be reduced by approximately $20-60 \%$ [3]. In addition to improving bone health through medication, future falls and fractures can be decreased by addressing other fracture risk factors, such as sarcopenia, frailty, low supply of dietary protein, poor muscle strength and power, inadequate dynamic balance, and environmental risks, such as safe walking environments [11]. Unfortunately, fracture management frequently does not include comprehensive fracture prevention strategies that integrate falls and fracture risk factors; however, it is of utmost importance to optimize clinician and patient engagement in fracture preventive services to decrease morbidity and mortality. Depending on the jurisdiction, multiple clinicians (physicians, rehabilitation specialists, psychologists, dietitians, etc.) and agencies (home care agencies, nursing homes) are responsible for management of adults at risk of falls and fracture. The aim of this paper therefore is to summarize the global state of the evidence for the rehabilitation of patients post-fragility fracture without cognitive impairment and to suggest directions for future research.

\section{Methods}

Members of the Rehabilitation Working Group of the International Osteoporosis Foundation Committee of Scientific Advisors proposed to address the broad topic of rehabilitation as an instrumental component of the treatment pathway post-fragility fracture. The goal of this narrative review is to serve as an overview and resource for the clinician seeking to support the rehabilitation of patients post-fragility fracture. Narrative reviews are ideally suited to this task [12]. This narrative review was developed independently by the authors, with funding sources having no role in the writing or editing of this document. Where available, systematic reviews, meta-analyses, and randomized controlled trials have been used to provide the evidence base. Searches were conducted in PubMed limited to English-language literature and studies conducted in humans from 2010 to August 2020 with primary sources being meta-analyses and systematic reviews of the post-fragility fracture rehabilitation literature and more recent trials not summarized in these reviews. Separate searches were conducted in the areas of exercise, physiotherapy, nutritional care, and patient education post-hip, vertebral, humeral, or wrist fragility fracture. The authorship team also searched health system factors relevant for understanding the episode of rehabilitation post-incident fracture including care transitions and care pathways post-fragility fracture.

\section{Overview of assessment}

All postmenopausal women and men age $\geq 50$ should be evaluated for osteoporosis risk to determine the need for BMD testing and vertebral imaging [3]. In clinical practice, osteoporosis is usually diagnosed by the BMD criteria or the occurrence of a fragility fracture. International guidelines recommend a comprehensive approach to risk assessment and diagnosis of osteoporosis which includes most of the following: a detailed history and physical examination, 
BMD assessment, vertebral imaging for vertebral fractures, and 10-year estimated fracture probability [3]. The diagnosis of osteoporosis requires the consideration of secondary causes. Many causes of bone loss and fractures can be grouped in the following broad categories: (1) Failure to develop a strong skeleton (genetics, nutrition, lifestyle), 2) loss of bone due to excessive breakdown (resorption), (3) failure to replace lost bone due to impaired formation, and (4) increased risk for falls (environmental, medical, and neuromusculoskeletal risk factors).

\section{Domains and sub-domains of assessment}

Increased risk for falls can be assessed by considering psychosocial-emotional (including cognition), physical function, nutrition, medication history, and environmental safety domains using a combination of subjective and objective assessments. An exhaustive review of assessment measures is beyond the scope of this review; however, we highlight several sub-domains to illustrate best practices. The psychosocial domain should include assessments of cognition, depression, fear, self-efficacy, and pain. Physical function is a broad concept that includes sub-domains of strength, balance, and endurance. In addition to individual assessment of sub-domains, physical function can be assessed through the successful completion of complex tasks such as activities of daily living. Nutrition can be screened through self-report, BMI measurement, food intake, blood biomarkers, and weight loss. Finally, measures of health-related quality of life can be used to describe a person's health status as represented on multiple domains that are central to overall health which can be specific to osteoporosis and its consequence or represent general concepts of wellbeing. Interested readers are directed to a comprehensive review on assessment of fall risk in primary care by Phelan et al. [13] for many of these concepts and to a Supplementary Appendix with examples of measures for use in domains and sub-domains listed above.

\section{Care pathways}

Treatment for osteoporosis should reflect the whole patient because declines in intrinsic capacity and functional ability are risk factors for fractures beyond bone mass [11]. The typical experience of an older adult with an extremity fracture begins with an emergency department presentation for acute medical management. The continuum of care for rehabilitation post-fragility fracture is complex, and improvements from rehabilitation can be realized as far out as 9- and 12-month post-fracture [14]. Common transitions from acute care include acute rehabilitation centers and typically a form of post-acute rehabilitation including inpatient rehabilitation, outpatient rehabilitation, sub-acute nursing facilities, or discharge home with supportive services. The form of post-acute rehabilitation depends in part on social support and the capacity to perform various intensities of daily rehabilitation [15]. It is common for patients to never return to pre-fracture levels of function, and as falls risks remain high, a secondary role of rehabilitation is to prevent falls and fall-related fractures in the post-acute phase [14].

\section{Models to address secondary fractures}

Secondary fractures and subsequent morbidity and mortality can be magnified by system-level problems. Different models have developed to address this problem, including orthogeriatric units and fracture liaison services [16]. These models of care are often limited to the coordination of inpatient services, and despite increased attention in the acute phase of care, delays in the initiation of rehabilitation exist and increase the risk for in-hospital mortality (OR 2.2, 95\% CI 1.06-4.42, $p$ value 0.034) [17].

Well-organized national and international campaigns have created robust fracture liaison services, such as Capture the Fracture $®$ (https://www.capturethefracture.org) [18], where great emphasis is placed on case identification, pharmaceutical management to strengthen bones, and falls risk identification and education to prevent subsequent fractures [19]. Fracture liaison programs have improved case identification and are associated with a decrease in future fractures. Though these programs often include falls risk assessment and education, a distinction should be made between the assessment of falls risk and education and initiating a comprehensive exercise or rehabilitation program. As suggested by age UK's 2013 falls prevention exercise guidelines, falls prevention exercise programs should be tailored to each patient's falls risk profile [20].

Below we review distinct elements of a comprehensive approach to post-fracture management including current evidence for exercise, physiotherapy, education, and nutrition.

\section{Exercise principles and characteristics}

Many studies describe exercise programs for the treatment and prevention of osteoporosis and its complications. The characteristics and principles upon which exercise studies are based for improving BMD are briefly described in Table 1. Mechanical load induced by exercise produces stress upon bones and enhances bone formation [21]. Figure 1 illustrates the interrelationship of BMD and loading principles. Progressive resistance exercise, weight-bearing impact training, and functional balance training are commonly prescribed modes of osteogenic exercise with 
Table 1 Loading characteristics and training principles to optimize bone health

\begin{tabular}{|c|c|c|}
\hline Key considerations & Description & Example \\
\hline Loading characteristics & $\begin{array}{l}\text { - Dynamic }>\text { static loads } \\
\text { - High intensity - function of strain (magnitude of defor- } \\
\text { mation and frequency of loading) } \\
\text { - Diverse load patterns } \\
\text { - Rest intervals }\end{array}$ & $\begin{array}{l}- \text { Drop landings }>\text { static stretching } \\
\text { 80-85\% 1RM, high velocity } \\
\text { - Multi-directional loading patterns } \\
\text { - 1-2-min rests between sets }\end{array}$ \\
\hline Specificity & $\begin{array}{l}\text { Bone adaptation to loading is specific to the site under } \\
\text { mechanical strain }\end{array}$ & $\begin{array}{l}\text { High impact jumping improves BMD at proximal femur, } \\
\text { but not lumbar spine }\end{array}$ \\
\hline Progressive overload & $\begin{array}{l}\text { Bone has a threshold level of adaptation, loads (strains) } \\
\text { above this level will stimulate bone formation }\end{array}$ & $\begin{array}{l}\text { The threshold value for osteogenic overload is proposed at } \\
\text { around ( } 1500 \text { micro strains), but it varies by individual } \\
\text { and between bone regions } \\
\text { Shifting from habitual walking } \sim 4 \mathrm{~km} / \mathrm{h}(\sim 2.5 \mathrm{mph} / \mathrm{h}) \text { to } \\
\text { brisk walking } 5-6 \mathrm{~km} / \mathrm{h}(3-4 \mathrm{mph} / \mathrm{h})\end{array}$ \\
\hline Reversibility & $\begin{array}{l}\text { Bone formation resulting from exercise training will be } \\
\text { slowly lost once the stimulus is discontinued }\end{array}$ & Reduction in physical activity is associated with bone loss \\
\hline Initial Values & $\begin{array}{l}\text { Greatest changes in BMD will occur in those with the } \\
\text { lowest initial BMD* }\end{array}$ & $\begin{array}{l}\text { Starting with lower BMD values produces greater } \\
\text { improvement hip BMD }\end{array}$ \\
\hline Diminished Returns & $\begin{array}{l}\text { Bone cells will respond strongly to a given load with suf- } \\
\text { ficient magnitude, but response will eventually phase out } \\
\text { with accommodation to the load }\end{array}$ & $\begin{array}{l}\text { Bone loses more mechanosensitivity after only a relatively } \\
\text { small number of loading cycles, } \sim 20\end{array}$ \\
\hline
\end{tabular}

*If relative intensity or pattern of loading is of a sufficient magnitude and rate or differs from everyday movement patterns, then bones should adapt accordingly, regardless of the initial values

Fig. 1 Illustration of exercise principles in relation to exercise induced gains in BMD

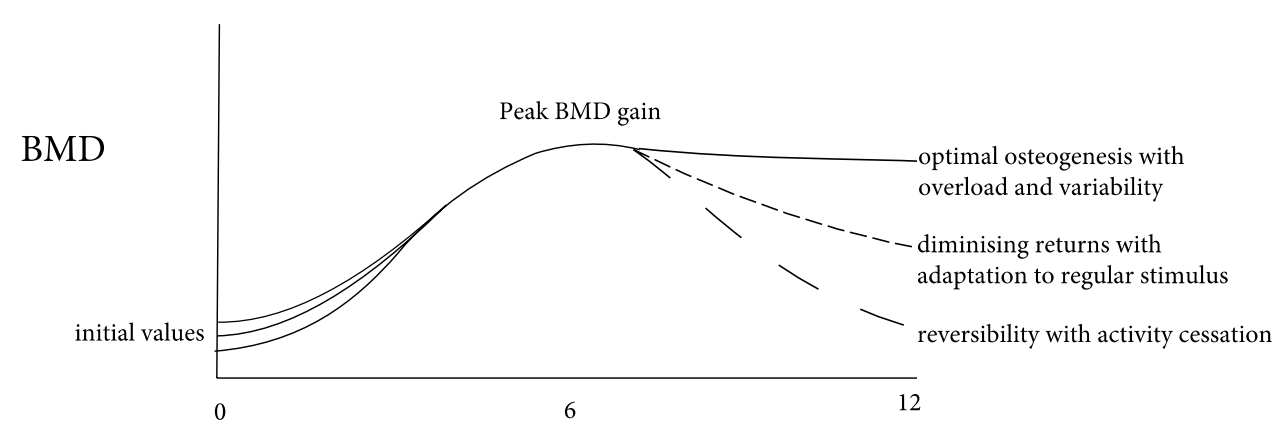

TIME (months) resistance exercise and impact training promoting the greatest bone formation.

Table 2 suggests general recommendations for osteogenic exercise prescription. It should be noted that the majority of evidence supporting these recommendations has been developed in a pre-fragility fracture population [22]; however, these criteria are being increasing applied to post-fracture populations with growing evidence for their principled use post-fracture [23]. Clinicians should consider applying these principles in the post-fragility fracture population, emphasizing correct technique, gradual loading increments, and avoidance of activities that might increase falls [24]. All clinicians prescribing exercise programs should consider the potential to load too aggressively increasing the likelihood of fracture [25]. All patients post-fragility fracture require initial focus at the level of transfer and mobility impairments prior to weight-bearing and standing balance activities. Slow progress or plateaus in rehabilitation [14] can be considered against meaningful exercise progression as suggested by these principles.

\section{Exercise post-fragility fracture of the vertebra}

Individuals with vertebral fractures may have a number of challenges including kyphosis, alterations in trunk muscle control, and pain which affects their participation in exercise, daily activities, and reduces quality of life. Randomized controlled trials (RCT) and metaanalyses have demonstrated that exercise improves quality of life, reduces pain, and improves physical function 
Table 2 Exercise parameters for managing patients at high risk of fragility fracture

\begin{tabular}{|c|c|c|c|}
\hline Training type & Dose & Recommendations & Precautions \\
\hline Progressive resistance training & $\begin{array}{l}\bullet \geq 2 \text { days/ week } \\
\bullet \geq 2 \text { sets of } 8-12 \text { repetitions } \\
\bullet 1-3 \text {-min rest between sets } \\
\bullet \geq 8 \text { exercises targeting major mus- } \\
\text { cle groups and common fracture } \\
\text { sites }\end{array}$ & $\begin{array}{l}\text { - Slow progression with empha- } \\
\text { sis on correct lifting technique }\end{array}$ & $\begin{array}{l}\text { - Consider vulnerable tissue when } \\
\text { training, e.g., the rotator cuff with } \\
\text { overhead lifting } \\
\text { - Use caution with trunk bending } \\
\text { or twisting for patients with low } \\
\text { spine BMD }\end{array}$ \\
\hline Weight-bearing impact training & $\begin{array}{l}\text { - } 4-7 \text { times per week } \\
\text { - 5-50 jumps per session (Build } \\
\text { capacity over time) } \\
\text { - } 5 \text { sets } \\
\text { - } 1-10 \text { repetitions } \\
\text { - } 1-2 \text {-min rest between sets }\end{array}$ & $\begin{array}{l}\text { - Increase jump and step height } \\
\text { - Change movement direction }\end{array}$ & $\begin{array}{l}\text { - Consider comorbid conditions } \\
\text { affected by impact exercises, e.g., } \\
\text { patients with incontinence or } \\
\text { arthritic joint pain }\end{array}$ \\
\hline $\begin{array}{l}\text { Functional balance, agility, and } \\
\text { coordination training }\end{array}$ & $\begin{array}{l}\text { - } 30 \text { min, } 4 \text { times/week } \\
\text { Examples include weight shifting, } \\
\text { single leg balance, turning and } \\
\text { stepping on and over objects. Can } \\
\text { manipulate vision, speed, direction, } \\
\text { multi-limb movements and cogni- } \\
\text { tive tasks }\end{array}$ & $\begin{array}{l}\text { - Must be progressive, challeng- } \\
\text { ing and supervised }\end{array}$ & $\begin{array}{l}\text { - Start with static and progress to } \\
\text { dynamic balance for patients with } \\
\text { impaired balance or with high risk } \\
\text { of fracture }\end{array}$ \\
\hline
\end{tabular}

Adapted suggested exercises from Beck et al. [24] and Daly et al. [22]

post-vertebral fractures [26]. However, the quality of the evidence is low, and little research exists for the effect of exercise in men with vertebral fractures [26].

\section{International recommendations/guidelines}

Clinicians often prescribe walking as a weight-bearing exercise for individuals with fractures; however, this does not specifically target vertebral BMD and risk for fracture. The Too Fit To Fracture recommendations [26] have stressed the importance of individuals with vertebral fractures to engage in a multi-component exercise program, including resistance training and balance training. A number of online resources are available; examples include those available at www.iofbonehealth.org and www.osteo porosis.ca. Due to the importance of a broad assessment of movement related impairments, a large international consensus has recommended that physical therapist consultations guide exercise prescription after a vertebral fracture, particularly for those with multiple vertebral fractures. Other recommendations include teaching of spine sparing techniques and daily balance training as well as endurance training for spinal extensors. Activities that involve rapid, repetitive, weighted, or end-range twisting or flexion of the spine, or that have high fall risk should be avoided; and the benefits from higher impact exercise may be outweighed by the risks of further injury [26].

\section{Supervised exercise}

A recent single-blinded RCT including women with a vertebral fracture focused on investigating the effects of a multi-component balance and resistance training program on walking speed as a primary outcome with secondary outcomes focused on quality of life, fear of falling, and other functional outcomes [27, 28]. A physiotherapist led a group of 8 to 10 women twice weekly for an hour for a total of 12 weeks. No statistically significant differences in walking speed were found, but significant improvements were found across all other functional outcomes [27, 28].

In a recent three-arm RCT including post-menopausal women with vertebral fracture, investigators compared a supervised program of back strengthening versus homebased program of back strengthening versus control. Groups of five participants under "full supervision of physiatrist" completed trunk extension exercises three times per week and performed 3 sets of 8 repetitions in weeks $1-2$ and increasing by two repetitions at 2 -week intervals until study completion at 6 weeks. The supervised exercise group had significantly lower spinal pain, greater muscle strength and endurance, and improved functional mobility and quality of life relative to home-based exercise program and control $(p<0.01)$ [29]. 


\section{Home-based exercise}

Few controlled trials have investigated home-based programs since the Too Fit To Fracture recommendations. A large feasibility multi-site RCT was undertaken to address the ability to recruit individuals with vertebral fracture and adherence to exercise. The build better bones (B3E) trial was a home-based exercise intervention that included resistance, balance, and posture exercises, and recommendations to perform daily moderate to vigorous aerobic physical activity for a minimum of $30 \mathrm{~min}$ on a daily basis over 12 months supervised by a physiotherapist (six visits). Typical prescriptions were $5-8$ exercises with a minimum of 2 sets of $8-10$ repetitions. Adherence to the intervention was $66 \%$ with falls and fractures not significantly different between groups [30].

A recent Cochrane review [31] found insufficient evidence for the effects of exercise on incident vertebral fractures or adverse events. Despite improvement in pain and disease-specific quality of life in individual trials, the findings were limited by low-quality evidence and imprecision [31]. Recommendations for future research include exercise interventions in males as few male participants have been included in trials to date.

\section{Exercise post-fragility fracture of the hip}

The main causes of morbidity post-fracture are a result of decreased mobility, impaired balance, and fear of falling [32], resulting in an increased risk of falls. Altogether, these causes prevent approximately $40 \%$ of older people from returning to pre-fracture daily activity, which are required for independence and safety [7]. The recuperation time of pre-fracture skills and capabilities can last up to 9 months for balance deficits and approximately 1 year for gait and walking speed. Exercise programs seek to address impairments related to mobility loss and reduced function.

\section{Intervention programs}

\section{Supervised exercise}

Systematic reviews and meta-analyses of progressive resistance exercise [33], balance training [34-36], and structured exercise [37] interventions all show moderate to large improvements in physical function compared with control groups in people post-hip fracture. Consistent with expectations from exercise training principles, structured exercise trials focusing on progressive resistance exercises had larger treatment effects on overall mobility (SMD $=0.58,95 \%$ CI 0.17 to $0.98, p=0.008$ ) [37], and balance training at high frequency was more effective for improving overall function than balance training at low frequency [35]. The LIFTMOR randomized trial is notable for including $28 \%$ of participants with a history of osteoporotic fracture when assessing a high intensity resistance training and impact training program, though exclusion criteria prohibited participation within the first year of fracture [38]. Impact loading consisted of jumping chin-ups with drop landings where participants were instructed to jump "as high as possible while simultaneously pulling themselves as high as possible with their arms. At the peak of the jump, the participant dropped to the floor, focusing on landing as heavily as comfortably possible." The study participants performed $30 \mathrm{~min}$ of exercise, twice weekly for 8 months. Relative to control, the high intensity and impact training group showed significant improvements in bone mass, femoral neck geometry, and physical function and reported no major adverse events. Auais, Eilayyan, and May performed a systematic review and meta-analysis on exercise programs that were longer-term or "extended" relative to traditional rehabilitation post-hip fracture and found a moderate improvement on physical performance-based tests $(\mathrm{ES}=0.53,95 \% \mathrm{CI}=0.27-0.78)[39]$.

\section{Home-based exercise}

Reviews of home-based exercise interventions show mixed results [34, 40, 41]. Two meta-analyses report mean improvement in function, and a third reported no difference using home-based exercise programs. Latham et al. showed significant, between-group improvements in performancebased and self-reported function at 9-month follow-up when adding a home exercise program to conventional rehabilitation relative to rehabilitation care alone [42].

Despite overall positive effects of exercise interventions, trials tend to be relatively small. and exercises are poorly described [33, 34] making reproducibility difficult. Exercise interventions are important tools in recovery post-fracture. We recommend clearer reporting and improving the research base of studies investigating exercise parameters on future falls, physical function, and bone formation post-fragility fracture, administered at different points in the post-operative continuum of care.

\section{Physiotherapy post-fragility fracture}

Physiotherapists employ a variety of strategies post-fragility fracture in addition to exercise including functional mobilization, transfer training, safety training, patient education, postural taping, manual therapy, and use of assistive devices $[43,44]$. To avoid duplication of previous sections focusing on exercise, this section highlights investigations of physiotherapy related to dosage, intensity, or multi-modal 
physiotherapy interventions that employ non-exercise modalities used in rehabilitation.

\section{Dosage, intensity, and setting}

High intensity physiotherapy for patients post-hip fracture has shown mixed results and has been defined in varying ways in the literature [45, 46]. Kimmel et al. investigated the effect of three daily physiotherapy, 30-min visits versus one daily $30-\mathrm{min}$ visit in acute rehabilitation. The intervention group experienced a significant improvement in level of assistance required $(p=0.04)$ and reduced hospital stay by over 10 hospital days [45]. Moseley, et al. [46] randomized individuals post-hip fracture to high intensity versus low intensity physiotherapy. The intervention began in the inpatient setting and progressed to the outpatient setting. No differences were found in the primary outcomes of walking speed or muscle strength; however, the main difference between high intensity and low intensity groups in the inpatient phase was time spent in treadmill walking, and the total difference between groups in the outpatient phase was a median of 4 days [46]. Physiotherapy services are administered in multiple settings, and no strong consensus exists for outpatient versus home setting in the management of hip [47] or wrist fracture [48].

\section{Behavioral approaches}

Multi-disciplinary rehabilitation programs have included behavioral approaches within the context of physiotherapy, such as the use of counselling sessions [49], workbooks and goal setting [50,51], motivational interviewing [52], and cognitive behavioral therapy [53]. In these examples, behavioral approaches were employed to support patient self-management [49-52] and decrease fear of falling [51, 53]. The motivational interviewing intervention increased objective physical activity versus usual care [52], and the psychologically-informed rehabilitation program improved patient participation (primary outcome) [51]. Unfortunately, no other approach showed significant differences in their main analyses. However, secondary analyses of physiotherapy employing counselling sessions increased physical activity [54] and improvements in physical disability [55] at 1-year follow-up.

\section{Manual therapy, taping, and orthoses}

Few studies have investigated the use of taping modalities and manual therapy in the post-fragility fracture population. Bennell et al. conducted a single blind, randomized controlled pilot trial assessing taping, manual therapy (soft tissue massage and joint mobilization), and exercise versus control in people with a history of painful vertebral fracture. Significant improvements were found in pain during movement and at rest and in physical function, quality of life questionnaire (QUALEFFO) physical function $(-4.8(-9.2$ to -0.5$))$ and the timed loaded standing test (46.7 (16.1 to 77.3) s) [56]. Barker et al. published an adaptive single-blinded randomized controlled trial assessing exercise therapy versus manual therapy approaches [57]. Participants were included if they had a diagnosis of primary osteoporosis, at least one previous vertebral fracture, with the ability to walk at least $10 \mathrm{~m}$ independently. This three-arm trial assessed seven individual physiotherapy sessions over 12 weeks for either manual therapy or home exercise versus one session of physiotherapist delivered education. At 4 months, significant improvements over education were found in the manual therapy and exercise groups, respectively, for the time loaded standing endurance test and functional reach test, but these improvements did not persist to 1-year follow-up [57]. The study suffered from low adherence to protocol: only $60 \%$ of exercise sessions and approximately $70 \%$ of manual therapy sessions were attended, and only $40 \%$ and $50 \%$ of the exercise and manual therapy groups fully complied with the protocol. Additionally, 25\% of education participants engaged in therapy outside of the trial [57].

Rehabilitation often includes coordinated assistive device management to support limited mobility. Assistive devices can serve as short-term or long-term measures of improving balance, activity level, and overall independence depending on potential for functional recovery. Key considerations in prescribing assistive devices are to prevent further complications by appropriately fitting the device to the patient and providing proper education and assessment of understanding for their use [58]. As instruments in the rehabilitation process, systematic reviews have investigated the use of spinal orthoses for vertebral osteoporosis including strategies assessed post-vertebral fracture [59]. Few studies have compared spinal orthoses with usual care despite their common use in clinical management. Spinal orthoses appear safe as a means to treat acute and sub-acute vertebral fracture, but there is no clear evidence of superiority for rigid versus soft braces [59]. A recent multi-center, RCT compared soft versus rigid bracing strategies with acute vertebral fracture and found no difference in anterior vertebral body compression at 48 weeks [60]. A recent feasibility study of taping relative to usual care showed a promising reduction in pain and improvement in function and quality of life [61].

Most reviews assessing the effects of physiotherapy report low quality of evidence mainly due to high risks of bias and small sample sizes. Several interventions currently used by physiotherapists have not been properly evaluated and warrant future randomized trials including orthoses, taping, and manual therapy. It is recommended that investigators of 
physiotherapy seek to identify optimal combinations of interventions, modalities, dosage, and setting.

\section{Fall prevention programs post-fragility fracture}

Fall prevention programs for community dwelling older adults are effective at reducing falls, hospitalizations, and associated medical costs [62] and are recommended for community implementation to improve public health [63]. Fall prevention programs typically include multi-modal exercise approaches and may include behavioral strategies and other forms of task training, such as transferring from the floor to upright stance [62]. Many of the components of falls programs have been described in previous sections of this paper; however, Tai Chi as a movement warrants further description given its popularity as a falls prevention intervention. Tai Chi was developed over 300 years ago in China, beginning as a form of martial arts, but today is mostly employed as a mind-body practice with three basic components: (1) body position should be extended and relaxed, focusing on awareness and alignment; (2) the mind should be alert but calm, increasing awareness of bodily movement in space; and (3) body movements require coordinated sequencing of segments from trunk and hips to extremities [64]. Tai Chi has been shown to be effective for decreasing falls in older adults [62]. Unfortunately, few fall prevention programs have been explicitly studied in the post-fragility fracture population with future fractures reported as an outcome. Likewise, despite evidence as a means to decrease falls in community dwelling older adults, little evidence exists for the use of Tai Chi in patients post-fragility fracture, and there are mixed results as a means to improve bone health [65].

\section{Nutritional care post-fragility fracture}

Malnutrition, in particular protein and caloric under-nutrition, are considered fracture risks by impairing muscle strength and function, thereby increasing the risk of falling. Compromised bone strength results in increased bone fragility and reduced soft tissue protection around the hip [66]. Malnutrition can also negatively influence fracture healing (mostly in animal studies) and rehabilitation by slowing down independence restoration, which increases risk of complications and disabilities and increases the risk of subsequent fracture.

\section{Nutritional status}

Pre-fracture nutritional status is predictive of functional status at discharge, of admission into nursing homes at 6 months [67], and of mortality at 6 months [68] and later
$[68,69]$. Mortality is increased more than twofold with malnutrition in patients with hip fracture [70]. The prevalence of malnutrition using weight loss, food intake, and BMI-based instruments depends on the age of the patients and the type of fracture. In patients attending a trauma ward, and with a mean age of 55 years, malnutrition prevalence was around $20 \%$ [71]. Prevalence increases to $40 \%$ in 65 years and older patients in an orthopedic clinic and more than $85 \%$ in elderly patients with hip fracture when both malnourished and at risk of malnutrition are analyzed together [68].

\section{Nutritional interventions (dietary, supplements)}

Controlled trials, which have investigated the influence of nutritional intervention after fracture (Table 3), include dietary counselling [72, 73], energy [74-76], protein supplements [77-87] such as casein or whey protein based [88], or protein enriched with hydroxymethyl butyrate, a metabolite of the amino acid leucine which has been shown to favorably influence muscle function by acting on the target of rapamycin (TOR) enzyme $[89,90]$. In a small pilot trial, essential amino acids were evaluated [91]. The doses of protein were between 17 and $40 \mathrm{~g} / \mathrm{day}$, correcting or overcoming protein intake deficiency. It appears that muscle protein synthesis requires more substrate in old as compared with young individuals [66]. Under these conditions, higher amounts of protein are recommended in older subjects, from a recommended daily allowance of $0.8 / \mathrm{kg}$ body weight to up to 1.3-1.5, in situations of stress or inflammation, where the needs are higher. Indeed, the PROT-AGE study group recommends 1.0 to $1.2 \mathrm{~g}$ protein per kilogram of body weight per day to help older adults maintain and regain lean body mass and function, and $\geq 1.2 \mathrm{~g} / \mathrm{kg}$ body weight/day is recommended for older adults who are exercising, and 1.2-1.5 g/ $\mathrm{kg}$ body weight/day is recommended for those with chronic disease[92].

\section{Dietary/supplements intervention post-fragility fracture}

Protein supplements increase insulin-like growth factor, IGF-I [79], which is considered as a marker of malnutrition. By 4 weeks of supplementation, it appears that maximal effects could be reached [93]. Regarding trials with clinically relevant outcomes, the trials have included hip fractured patients with a mean age above 80 years, representing thereby typical hip fractured patients. The number of patients varied between 23 and 420, with durations between 1 week and 12 months (Table 3). Some studies have shown a decrease in medical complications [77, 78, 80, 84] such as 
Table 3 Effects of nutritional supplements on clinical outcomes after hip fracture (selected controlled trials)

\begin{tabular}{|c|c|c|c|c|}
\hline Author year ${ }^{\text {(ref) }}$ & $N$ mean age & $\begin{array}{l}\text { Duration } \\
\text { (months) }\end{array}$ & Supplements & Outcome \\
\hline Delmi, 1990 [77] & $59,81.6$ years & 1 & $\begin{array}{l}\text { Prot } 20 \mathrm{~g} / \text { day } \\
254 \mathrm{kcal} / \text { day }\end{array}$ & $\begin{array}{l}\text { Complications: } 16 \text { vs } 37 \% \text { ( } 6 \mathrm{Mo}) \\
\text { Median LoS: }-40 \% \\
\text { Mortality: } 24 \text { vs } 37 \% \text { ( } 6 \mathrm{Mo})\end{array}$ \\
\hline Tkatch, 1992 [78] & 62,82 years & 1.3 & Prot 20 g/day & $\begin{array}{l}\text { Complications and deaths: } 52 \text { vs } 80 \% \text { ( } 7 \mathrm{Mo} \text { ) } \\
\text { Median Los: }-32 \%\end{array}$ \\
\hline Schürch, 1998 [79] & $82,80.7$ years & 6 & Prot 20 g/day & $\begin{array}{l}\text { LoS (Rehab.): }-39 \% \\
\partial \text { Femoral neck BMD: } 2.4 \% \text { (12 Mo) } \\
\partial \text { IGF-I: } 51 \% \text { (6 Mo) }\end{array}$ \\
\hline Espaulella, $2000[80]$ & $171,82.6$ years & 2 & Prot 20 g/day & Complications (6 Mo): 55 vs $70 \%$ (in-hospital and at $6 \mathrm{Mo}$ ) \\
\hline Houwing, 2003 [81] & $103,81.0$ years & 1 & $\begin{array}{l}\text { Prot } 40 \mathrm{~g} / \text { day } \\
500 \mathrm{kcal} / \text { day }\end{array}$ & Pressure ulcers stage II: $-9 \%$ \\
\hline Sullivan, 2004 [74] & $57,79.0$ years & 6 & $\begin{array}{l}1375 \mathrm{kcal} / \mathrm{d} \\
\text { nasogatric, orally }\end{array}$ & No $\partial$ complications nor mortality \\
\hline Tidermark, 2004 [82] & $60,82.9$ years & 12 & $\begin{array}{l}\text { Prot } 20 \text { g/day } \\
200 \mathrm{kcal} / \text { day }\end{array}$ & $\partial \operatorname{ADL}(6 \mathrm{Mo})$ \\
\hline Hommel, 2007 [75] & $420,81.0$ years & 0.3 & $250 \mathrm{kcal} /$ day & Pressure ulcers: 9 vs $18.6 \%$ \\
\hline Tengstrand, 2007 [83] & $60,82.9$ years & 6 & Prot $20 \mathrm{~g} /$ day & $\partial \mathrm{BMD}(12 \mathrm{Mo})$ \\
\hline Gunnarsson, 2009 [76] & $100,81.0$ years & 0.17 & $\begin{array}{l}30 \mathrm{kcal} / \mathrm{kg} / \text { day } \\
\text { Nasogastric }\end{array}$ & Pressure ulcers: 18 vs $36 \%$ \\
\hline Botella-Carretero, 2010 [84] & $60,83.6$ years & 0.33 & Prot 40 g/day & Complications: $-7.5 \%$ \\
\hline Myint, 2013 [85] & $121,81.3$ years & 1 & Prot $+18-24 \mathrm{~g} / \mathrm{d}$ ay & $\begin{array}{l}\text { Maintained body mass index } \\
\text { Infections: }-52 \% \\
\text { LoS: }-13 \%\end{array}$ \\
\hline $\mathrm{Li}, 2013$ [73] & $162,78.2$ years & 12 & Diet counselling & Better ADL and walking capacity \\
\hline Flodin, 2015 [86] & $79,81.0$ years & 6 & $\begin{array}{l}\text { Prot } 40 \mathrm{~g} / \text { day } \\
600 \mathrm{kcal} / \text { day }\end{array}$ & No $\partial$ in lean mass nor EQ-5D \\
\hline Ekinci, 2016 [89] & $62,82.6$ years & 1 & $\begin{array}{l}\text { Prot } 36 \text { g/day } \\
\text { HBM } 3 \text { g/day }\end{array}$ & $\begin{array}{l}\text { Shorter wound healing period } \\
\text { Mobility: } 81 \text { vs } 27 \% \text { ( } 1 \mathrm{Mo}) \\
\text { Higher muscle strength }\end{array}$ \\
\hline Niitsu, 2016 [88] & $38,79.7$ years & 0.5 & Whey prot $32.2 \mathrm{~g} /$ day & $\begin{array}{l}\text { Higher lower limbs muscle strength } \\
\text { Better Barthel index }\end{array}$ \\
\hline Malafarina, 2017 [90] & $107,85.4$ years & 1.5 & $\begin{array}{l}\text { Prot } 40 \mathrm{~g} / \text { day } \\
\text { HBM } 3.1 \mathrm{~g} / \text { day }\end{array}$ & Maintained body weight and appendicular lean mass \\
\hline Wyers, 2018 [87] & $152,78.5$ years & 3 & $\begin{array}{l}\text { Prot } 40 \mathrm{~g} / \text { day } \\
500 \mathrm{kcal} / \text { day }\end{array}$ & No $\partial$ in LoS nor in clinical outcomes \\
\hline Invernizzi, 2018 [91] & $32,79.0$ years & 2 & EAA 8 g/day & $\begin{array}{l}\text { No } \partial \text { in functional outcomes (grip strength, time-up, and go } \\
\text { test) }\end{array}$ \\
\hline
\end{tabular}

$A D L$ activities of daily living; $B M D$ bone mineral density; $E A A$ essential amino acids; $E Q-5 D$ EuroQol instrument for quality of life evaluation; $I G F-I$ insulin-like growth factor; $L o S$ length of stay

fewer pressure ulcers and shorter wound healing times [75, $76,81]$, fewer infections [85], reduced length of stay [77-79, 85], lower mortality [77, 78], a preservation of BMD [79, 83], improvements in ADLs [82], and better muscle function [73]. The results are heterogeneous with a low consistency, likely in relation to the small number of patients in some trials, different follow-up durations, variability in outcomes, and differences in interventions. The effects of nutritional supplements in hip fractured patients have been evaluated in 2 meta-analyses including different numbers of studies (Table 4) [94, 95]. Medical complications, wound, respiratory, and urinary infections were significantly reduced
[94], as well as overall unfavorable outcomes including both deaths and medical complications [95].

\section{Fracture liaison services (FLS) support nutritional management}

To manage the correction of malnutrition in fractured patients, a critical pathway aimed at detecting malnutrition and offering re-nutrition either through dietary changes or supplements should be a full part of fracture liaison services, not only to improve short- and middle-term rehabilitation 
Table 4 The role of perioperative oral nutritional supplementation in elderly patients after hip surgery

\begin{tabular}{|c|c|c|c|c|c|c|}
\hline Ref & Outcome & Trials $(n)$ & $\begin{array}{l}\text { Oral nutritional } \\
\text { supplements }(n)\end{array}$ & Controls $(n)$ & $\begin{array}{l}\text { Relative risk with oral } \\
\text { nutritional supplements }\end{array}$ & $95 \% \mathrm{CI}$ \\
\hline \multirow[t]{5}{*}{ [94] } & $\begin{array}{l}\text { Complications* (e.g. all infections, bed sores, } \\
\text { cardiac disease, cognitive impairment) }\end{array}$ & 6 & $55 / 220$ & $97 / 243$ & 0.49 & $0.32-0.73$ \\
\hline & Wound infection" & 3 & $1 / 97$ & $10 / 102$ & 0.17 & $0.04-0.79$ \\
\hline & Respiratory infection" & 3 & $2 / 100$ & $10 / 100$ & 0.26 & $0.07-0.94$ \\
\hline & Urinary infection" & 3 & $2 / 100$ & $10 / 100$ & 0.22 & $0.05-0.90$ \\
\hline & Mortality* & 5 & $35 / 198$ & $39 / 218$ & 1.02 & $0.62-1.70$ \\
\hline \multirow[t]{4}{*}{ [95] } & Mortality* & 15 & $24 / 486$ & $31 / 82$ & 0.81 & $0.49-1.31$ \\
\hline & $\begin{array}{l}\text { Complications* (pressure sore, infections, venous } \\
\text { thrombosis, pulmonary embolism, confusion) }\end{array}$ & 11 & $157 / 367$ & $123 / 370$ & 0.71 & $0.59-0.86$ \\
\hline & Unfavorable outcome* (deaths or complications) & 6 & $58 / 176$ & $67 / 158$ & 0.67 & $0.51-0.89$ \\
\hline & GI side effects** (vomiting and diarrhea) & 6 & $18 / 231$ & $11 / 211$ & 0.99 & $0.47-2.05$ \\
\hline
\end{tabular}

*Follow-up: 1-12 months. "Follow-up: 1 month or until hospital discharge. **Follow-up: during supplementation period

outcomes, but also as an integrated component of secondary fracture prevention $[18,19,96]$. Future investigations in the role of nutritional management within FLS are encouraged.

\section{Patient education}

Patient education is a recognized component to the management of many chronic diseases, and its role in post-fracture management has been reviewed in two systematic reviews [97, 98]. In the first, published in 2014 by Jensen and colleagues [97], the authors report on the results of 7 studies ( 2 observational studies and 5 randomized controlled trials) published between 1993 and 2011 that included patients with osteoporosis with or without fractures who were involved in group education packages. There was good geographic representation, with studies originating from Europe $(n-=3)$, North America $(n=3)$, and Australia $(n=1)$. Participants were recruited from outpatient clinics $(n=5)$, a retirement community $(n=1)$, and an emergency department $(n=1)$. The sample size of each study ranged from 50 to 300 participants; 849 women but only 74 men were recruited. Group sizes, where stated, ranged from 4 to 20 individuals; programs lasted from 5 to $27 \mathrm{~h}$, running 1-2 times per week for $4-5$ weeks, with the number of educators ranging from 1 to 4 .

The content of the schemes was similar, and consisted of three overall themes: knowledge of osteoporosis, medication, and diet and exercise. Activities of daily living, pain management, and fall prevention also were featured in some. In five of the included studies, theories of empowerment, self-management, action planning, self-efficacy, and coping were used. Heterogeneity in the outcome measures used made overall assessment challenging, but the authors concluded that multi-faceted osteoporosis group education can increase a patients' knowledge of osteoporosis, health-related quality of life, physical activity, and psychosocial functioning, and may also be a way to increase adherence to both pharmacological and non-pharmacological treatments, as it was reported that participants who attended a four-session group adhered better to medication subsequently, although calcium intake was no different between the two groups. There was also some evidence of benefit with regard to pain and physical activity outcomes. Interestingly, only two studies considered knowledge as an outcome, and in both cases, this improved with education. Hence, in this review, there was evidence of benefit in group education sessions, but varying methodology made it difficult to synthesize evidence, and the few data available in men was a significant limitation. Qualitative studies were excluded from this report, but their potential contribution to the topic was acknowledged.

In the second more recent systematic review by Morfeld and colleagues [98], limitations of methodology were highlighted, with the need for further research acknowledged. They reviewed randomized controlled trials published between 2001 and 2013, identifying 15 articles (of 13 studies), that included 7 considering group-based education, 5 that considered individual education and one that considered both. The general risk of bias was considered as moderate to high, and the authors report that differences between the intervention and control groups with regard to pharmacological therapy, medication adherence, physical activity, fractures, and quality of life were found to be statistically significant in less than $50 \%$ of the trials. Once again, there was evidence of recruitment worldwide, with men and women participating. As in the previous systematic review, a wide variety of outcome tools and measures were reported, making comparisons difficult. When comparing adherence rates across trials, substantial variation was apparent with proportions of adherent patients varying between 16 to $92 \%$ in the intervention group and $22 \%$ to $80 \%$ in the control group. 
Patient education appears to be an attractive tool in the management of osteoporosis and has been highlighted as an area of unmet need among patients with osteoporosis and fragility fracture [99]. However, the two available systematic reviews have highlighted the need for randomized controlled trials that clearly report education packages and randomize interventions appropriately, and for researchers to find consensus on outcomes measures, and how they might be assessed. The potential for benefit in placing the patient at the center of their management is very considerable, as demonstrated by a randomized controlled trial, the PREVOST study, where this approach, coupled with a case manager, led to a $20 \%$ uplift in BMD measurement in patients who had sustained a humeral fracture [100]. In addition, education is mandatory for patient engagement with physiotherapy and dietary changes.

\section{Recommendations for future research}

This paper reviews current evidence for rehabilitation following a fragility fracture. The areas of rehabilitation highlighted above are each a group of complex interventions, built up from a number of components that may act independently and inter-dependently. Together, they serve to build functional capacity and decrease the risk of future fracture. Research investigating these relationships will reinforce a comprehensive approach to clinical management. Gaps in the literature of complex interventions have been identified including clinical trial methodology and gaps between research evidence, clinical practice, and health policy. These gaps continue to exist in rehabilitation post-fragility fracture, particularly with respect to gaps between evidence and practice. We would like researchers to consider features of participatory research processes and the importance of implementation during intervention development.

Specific areas that we believe need further study are:

- Development of individualized exercise approaches considering patient preferences and integrating factors associated with patient adherence

- Trials to define the exercise regimens that create the greatest reduction in kyphosis and pain after vertebral fracture

- Trials to define the exercise regimens using multi-disciplinary/collaborative approaches to ensure the best recovery and the lowest length of stay in rehabilitation units, including formal incorporation of psychosocial constructs such as fear and self-efficacy

- A greater understanding of the specific educational needs of patients and caregivers, which may require the employment of qualitative approaches
- Study of rehabilitation strategies across the continuum of care including characterization of rehabilitation dosage and transition between rehabilitation settings

- Characterization of the relationship between malnutrition, fracture healing, rehabilitation, and future fracture risk

- Trials of rehabilitation implementation strategies associated with fracture liaison services for secondary fracture prevention

Supplementary Information The online version contains supplementary material available at https://doi.org/10.1007/s00198-021-06240-7.

Acknowledgements This work was supported by the International Osteoporosis Foundation (IOF) and undertaken through the Rehabilitation Working Group of the IOF Committee of Scientific Advisers.

Rehabilitation Working Group of IOF members:

Chairs:

O Bruyère

D Pinto

Members:

R Blank

B Buehring

R Chapurlat

T Chevalley

C Cooper

E Dennison

S Ferrari

JA Kanis

JF Kaux

NE Lane

OD Messina

J Morales Torres

BM Camargos

J Paccou

A Papaioannou

JY Reginster

R Rizzoli

S Silverman

Ş Tüzün

Funding This work was supported by the International Osteoporosis Foundation (IOF) and undertaken through the Rehabilitation Working Group of the IOF Committee of Scientific Advisors.

\section{Declarations}

Conflict of interest The authors declare no competing interests.

\section{References}

1. Black DM, Rosen CJ (2016) Postmenopausal osteoporosis. N Engl J Med 374(21):2096-2097

2. Johnell O, Kanis JA (2006) An estimate of the worldwide prevalence and disability associated with osteoporotic fractures. Osteoporos Int 17(12):1726-1733

3. Kanis JA, Cooper C, Rizzoli R, Reginster JY, (IOF) SABotESfCaEAoOEatCoSAaNSotIOF (2019) European guidance for the 
diagnosis and management of osteoporosis in postmenopausal women. Osteoporos Int. 30(1):3-44

4. Curtis EM, van der Velde R, Moon RJ, van den Bergh JP, Geusens P, de Vries F et al (2016) Epidemiology of fractures in the United Kingdom 1988-2012: variation with age, sex, geography, ethnicity and socioeconomic status. Bone 87:19-26

5. Burge R, Dawson-Hughes B, Solomon DH, Wong JB, King A, Tosteson A (2007) Incidence and economic burden of osteoporosis-related fractures in the United States, 2005-2025. J Bone Miner Res 22(3):465-475

6. Svedbom A, Hernlund E, Ivergard M, Compston J, Cooper C, Stenmark J et al (2013) Osteoporosis in the European Union: a compendium of country-specific reports. Arch Osteoporos 8(1-2). https://doi.org/10.1007/s11657-013-0137-0

7. Magaziner J, Simonsick EM, Kashner TM, Hebel JR, Kenzora JE (1990) Predictors of functional recovery one year following hospital discharge for hip fracture: a prospective study. J Gerontol 45(3):M101-M107

8. Cooper C, Atkinson EJ, Jacobsen SJ, O'Fallon WM, Melton LJ 3rd (1993) Population-based study of survival after osteoporotic fractures. Am J Epidemiol 137(9):1001-1005

9. Ioannidis G, Papaioannou A, Hopman WM, Akhtar-Danesh N, Anastassiades T, Pickard L et al (2009) Relation between fractures and mortality: results from the Canadian Multicentre Osteoporosis Study. Can Med Assoc J 181(5):265-271

10. van der Velde RY, Wyers CE, Geusens PPMM, van den Bergh JPW, de Vries F, Cooper C et al (2018) Incidence of subsequent fractures in the UK between 1990 and 2012 among individuals 50years or older. Osteoporosis Int 29(11):2469-2475

11. Blain H, Masud T, Dargent-Molina P, Martin FC, Rosendahl E, van der Velde $\mathrm{N}$ et al (2016) A comprehensive fracture prevention strategy in older adults: the European Union Geriatric Medicine Society (EUGMS) statement. Aging Clin Exp Res 28(4):797-803

12. Baethge C, Goldbeck-Wood S, Mertens S (2019) SANRA-a scale for the quality assessment of narrative review articles. Res Integr Peer Rev 4:5

13. Phelan EA, Mahoney JE, Voit JC, Stevens JA (2015) Assessment and management of fall risk in primary care settings. Med Clin North Am 99(2):281-293

14. Sheehan KJ, Smith TO, Martin FC, Johansen A, Drummond A, Beaupre L et al (2019) Conceptual framework for an episode of rehabilitative care after surgical repair of hip fracture. Phys Ther 99(3):276-285

15. Beaupre, L. (2011). Functional Recovery (Rehabilitation). In J. Waddell (Ed.), National Hip Fracture Toolkit. Bone and Joint Canada. http://boneandjointcanada.com/wp-content/uploads/ 2014/05/National-hip-fracture-toolkit-June-2011.pdf

16. Sabharwal S, Wilson H (2015) Orthogeriatrics in the management of frail older patients with a fragility fracture. Osteoporos Int 26(10):2387-2399

17. FrenkelRutenberg T, Vitenberg M, Haviv B, Velkes S (2018) Timing of physiotherapy following fragility hip fracture: delays cost lives. Arch Orthop Trauma Surg 138(11):1519-1524

18. Akesson K, Marsh D, Mitchell PJ, McLellan AR, Stenmark J, Pierroz DD et al (2013) Capture the Fracture: a Best Practice Framework and global campaign to break the fragility fracture cycle. Osteoporos Int 24(8):2135-2152

19. Javaid MK, Kyer C, Mitchell PJ, Chana J, Moss C, Edwards MH et al (2015) Effective secondary fracture prevention: implementation of a global benchmarking of clinical quality using the IOF Capture the Fracture(R) Best Practice Framework tool. Osteoporos Int 26(11):2573-2578
20. MacIntyre, D. (2017). Falls and fracture consensus statement: Supporting commissioning for prevention. Retrieved 3 March 2020, from https://assets.publishing.service.gov.uk/gover nment/uploads/system/uploads/attachment_data/file/586382/ falls_and_fractures_consensus_statement.pdf

21. Drinkwater BL (1994) C. H. McCloy Research Lecture: does physical activity play a role in preventing osteoporosis? Res Q Exerc Sport 65(3):197-206

22. Daly RM, Dalla Via J, Duckham RL, Fraser SF, Helge EW (2019) Exercise for the prevention of osteoporosis in postmenopausal women: an evidence-based guide to the optimal prescription. Braz J Phys Ther 23(2):170-180

23. Singh NA, Quine S, Clemson LM, Williams EJ, Williamson DA, Stavrinos TM et al (2012) Effects of high-intensity progressive resistance training and targeted multidisciplinary treatment of frailty on mortality and nursing home admissions after hip fracture: a randomized controlled trial. J Am Med Dir Assoc 13(1):24-30

24. Beck BR, Daly RM, Singh MA, Taaffe DR (2017) Exercise and sports science Australia (ESSA) position statement on exercise prescription for the prevention and management of osteoporosis. J Sci Med Sport 20(5):438-445

25. Pegrum J, Crisp T, Padhiar N, Flynn J (2012) The pathophysiology, diagnosis, and management of stress fractures in postmenopausal women. Phys Sportsmed 40(3):32-42

26 Giangregorio LM, Macintyre NJ, Thabane L, Skidmore CJ, Papaioannou A (2013) Exercise for improving outcomes after osteoporotic vertebral fracture. Cochrane Database Syst Rev 1:CD008618

27. Stanghelle B, Bentzen H, Giangregorio L, Pripp AH, Skelton DA, Bergland A (2020) Effects of a resistance and balance exercise programme on physical fitness, health-related quality of life and fear of falling in older women with osteoporosis and vertebral fracture: a randomized controlled trial. Osteoporos Int 31(6):1069-1078

28. Stanghelle B, Bentzen H, Giangregorio L, Pripp AH, Skelton DA, Bergland A (2020) Physical fitness in older women with osteoporosis and vertebral fracture after a resistance and balance exercise programme: 3 -month post-intervention follow-up of a randomised controlled trial. BMC Musculoskelet Disord 21(1):471

29. Cergel Y, Topuz O, Alkan H, Sarsan A, Sabir AN (2019) The effects of short-term back extensor strength training in postmenopausal osteoporotic women with vertebral fractures: comparison of supervised and home exercise program. Arch Osteoporos 14(1):82

30. Giangregorio LM, Gibbs JC, Templeton JA, Adachi JD, Ashe MC, Bleakney RR et al (2018) Build better bones with exercise (B3E pilot trial): results of a feasibility study of a multicenter randomized controlled trial of 12 months of home exercise in older women with vertebral fracture. Osteoporos Int 29(11):2545-2556

31 Gibbs JC, MacIntyre NJ, Ponzano M, Templeton JA, Thabane L, Papaioannou A et al (2019) Exercise for improving outcomes after osteoporotic vertebral fracture. Cochrane Database Syst Rev 7:CD008618

32. Shumway-Cook A, Ciol MA, Gruber W, Robinson C (2005) Incidence of and risk factors for falls following hip fracture in community-dwelling older adults. Phys Ther 85(7):648-655

33 Lee SY, Yoon BH, Beom J, Ha YC, Lim JY (2017) Effect of lower-limb progressive resistance exercise after hip fracture surgery: a systematic review and meta-analysis of randomized controlled studies. J Am Med Dir Assoc 18(12):1096.e19-.e26

34. Chen X, Yang W, Wang X (2020) Balance training can enhance hip fracture patients' independence in activities of daily living: 
a meta-analysis of randomized controlled trials. Medicine (Baltimore). 99(16):e19641

35. Wu JQ, Mao LB, Wu J (2019) Efficacy of balance training for hip fracture patients: a meta-analysis of randomized controlled trials. J Orthop Surg Res 14(1):83

36. Lee SY, Jung SH, Lee SU, Ha YC, Lim JY (2019) Effect of balance training after hip fracture surgery: a systematic review and meta-analysis of randomized controlled studies. J Gerontol A Biol Sci Med Sci 74(10):1679-1685

37. Diong J, Allen N, Sherrington C (2016) Structured exercise improves mobility after hip fracture: a meta-analysis with metaregression. Br J Sports Med 50(6):346-355

38. Watson SL, Weeks BK, Weis LJ, Harding AT, Horan SA, Beck BR (2018) High-Intensity resistance and impact training improves bone mineral density and physical function in postmenopausal women with osteopenia and osteoporosis: the LIFTMOR randomized controlled trial. J Bone Miner Res 33(2):211-220

39. Auais MA, Eilayyan O, Mayo NE (2012) Extended exercise rehabilitation after hip fracture improves patients' physical function: a systematic review and meta-analysis. Phys Ther 92(11):1437-1451

40. Wu D, Zhu X, Zhang S (2018) Effect of home-based rehabilitation for hip fracture: a meta-analysis of randomized controlled trials. J Rehabil Med 50(6):481-486

41. Chen B, Hu N, Tan JH (2020) Efficacy of home-based exercise programme on physical function after hip fracture: a systematic review and meta-analysis of randomised controlled trials. Int Wound J 17(1):45-54

42. Latham NK, Harris BA, Bean JF, Heeren T, Goodyear C, Zawacki $S$ et al (2014) Effect of a home-based exercise program on functional recovery following rehabilitation after hip fracture: a randomized clinical trial. JAMA 311(7):700-708

43. Thomas S, Mackintosh S, Halbert J (2011) Determining current physical therapist management of hip fracture in an acute care hospital and physical therapists' rationale for this management. Phys Ther 91(10): 1490-1502

44. Mangione KK, Lopopolo RB, Neff NP, Craik RL, Palombaro KM (2008) Interventions used by physical therapists in home care for people after hip fracture. Phys Ther 88(2):199-210

45. Kimmel LA, Liew SM, Sayer JM, Holland AE (2016) HIP4Hips (high intensity physiotherapy for hip fractures in the acute hospital setting): a randomised controlled trial. Med J Aust 205(2):73-78

46. Moseley AM, Sherrington C, Lord SR, Barraclough E, St George RJ, Cameron ID (2009) Mobility training after hip fracture: a randomised controlled trial. Age Ageing 38(1):74-80

47. Mehta SP, Roy JS (2011) Systematic review of home physiotherapy after hip fracture surgery. J Rehabil Med 43(6):477-480

48 Handoll HH, Elliott J (2015) Rehabilitation for distal radial fractures in adults. Cochrane Database Syst Rev. 9:CD003324

49. Edgren J, Salpakoski A, Sihvonen SE, Portegijs E, Kallinen M, Arkela M et al (2015) Effects of a home-based physical rehabilitation program on physical disability after hip fracture: a randomized controlled trial. J Am Med Dir Assoc. 16(4):350 e1-7

50. Williams NH, Roberts JL, Din NU, Totton N, Charles JM, Hawkes CA et al (2016) Fracture in the Elderly Multidisciplinary Rehabilitation (FEMuR): a phase II randomised feasibility study of a multidisciplinary rehabilitation package following hip fracture. BMJ Open. 6(10):e012422

51. Asplin G, Carlsson G, Ziden L, Kjellby-Wendt G (2017) Early coordinated rehabilitation in acute phase after hip fracture - a model for increased patient participation. BMC Geriatr 17(1):240

52. O'Halloran PD, Shields N, Blackstock F, Wintle E, Taylor NF (2016) Motivational interviewing increases physical activity and self-efficacy in people living in the community after hip fracture: a randomized controlled trial. Clin Rehabil 30(11):1108-1119
53. Scheffers-Barnhoorn MN, van Eijk M, van Haastregt JCM, Schols J, van Balen R, van Geloven N et al (2019) Effects of the FIT-HIP intervention for fear of falling after hip fracture: a cluster-randomized controlled trial in geriatric rehabilitation. J Am Med Dir Assoc. 20(7):857-65 e2

54. Turunen K, Salpakoski A, Edgren J, Tormakangas T, Arkela M, Kallinen M et al (2017) Physical activity after a hip fracture: effect of a multicomponent home-based rehabilitation program-a secondary analysis of a randomized controlled trial. Arch Phys Med Rehabil 98(5):981-988

55. Salpakoski A, Tormakangas T, Edgren J, Kallinen M, Sihvonen SE, Pesola M et al (2014) Effects of a multicomponent homebased physical rehabilitation program on mobility recovery after hip fracture: a randomized controlled trial. J Am Med Dir Assoc 15(5):361-368

56. Bennell KL, Matthews B, Greig A, Briggs A, Kelly A, Sherburn $M$ et al (2010) Effects of an exercise and manual therapy program on physical impairments, function and quality-of-life in people with osteoporotic vertebral fracture: a randomised, single-blind controlled pilot trial. BMC Musculoskelet Disord 11:36

57. Barker KL, Newman M, Stallard N, Leal J, Lowe CM, Javaid MK et al (2020) Physiotherapy rehabilitation for osteoporotic vertebral fracture-a randomised controlled trial and economic evaluation (PROVE trial). Osteoporos Int 31(2):277-289

58. Bradley SM, Hernandez CR (2011) Geriatric assistive devices. Am Fam Physician 84(4):405-411

59 Hofler RC, Jones GA (2020) Bracing for acute and subacute osteoporotic compression fractures: a systematic review of the literature. World Neurosurg 141:e453-e460

60. Kato T, Inose H, Ichimura S, Tokuhashi Y, Nakamura H, Hoshino $\mathrm{M}$ et al (2019) Comparison of Rigid and soft-brace treatments for acute osteoporotic vertebral compression fracture: a prospective, randomized, multicenter study. J Clin Med 8(2):198

61. Palmer S, Barnett S, Cramp M, Berry A, Thomas A, Clark EM (2018) Effects of postural taping on pain, function and quality of life following osteoporotic vertebral fractures-A feasibility trial. Musculoskeletal Care 16(3):345-352

62 Sherrington C, Fairhall NJ, Wallbank GK, Tiedemann A, Michaleff ZA, Howard K et al (2019) Exercise for preventing falls in older people living in the community. Cochrane Database Syst Rev 1:CD012424

63. Li F, Eckstrom E, Harmer P, Fitzgerald K, Voit J, Cameron KA (2016) Exercise and fall prevention: narrowing the research-topractice gap and enhancing integration of clinical and community practice. J Am Geriatr Soc 64(2):425-431

64. Wolf SL, Coogler C, Xu T (1997) Exploring the basis for Tai Chi Chuan as a therapeutic exercise approach. Arch Phys Med Rehabil 78(8):886-892

65. Sun Z, Chen H, Berger MR, Zhang L, Guo H, Huang Y (2016) Effects of tai chi exercise on bone health in perimenopausal and postmenopausal women: a systematic review and meta-analysis. Osteoporos Int 27(10):2901-2911

66. Rizzoli R (2014) Nutritional aspects of bone health. Best Pract Res Clin Endocrinol Metab 28(6):795-808

67 Miu MKYD, Lam PS (2017) Effects of nutritional status on 6-month outcome of hip fractures in elderly patients. Ann Rehab Med 41(6): 1005-12

68. Koren-Hakim T, Weiss A, Hershkovitz A, Otzrateni I, Anbar R, Gross Nevo RF et al (2016) Comparing the adequacy of the MNA-SF, NRS-2002 and MUST nutritional tools in assessing malnutrition in hip fracture operated elderly patients. Clin Nutr 35(5):1053-1058

69 Malafarina V, Reginster JY, Cabrerizo S, Bruyere O, Kanis JA, Martinez JA et al (2018) Nutritional status and nutritional treatment are related to outcomes and mortality in older adults with hip fracture. Nutrients. 10(5):555 
70. Bell BJJ, Pulle RC, Crouch AM, Kuys SS, Ferrier RL, Whitehouse SL (2016) Impact of malnutrition on 12-month mortality following acute hip fracture. ANZ J Surg 86(3):157-61

71. Ihle C, Freude T, Bahrs C, Zehendner E, Braunsberger J, Biesalski HK et al (2017) Malnutrition - An underestimated factor in the inpatient treatment of traumatology and orthopedic patients: A prospective evaluation of 1055 patients. Injury 48(3):628-636

72 Milne MAC, Avenell A, Potter J (2006) Meta-analysis: protein and energy supplementation in older people. Ann Intern Med 144(1):37-48

73. Li HJ, Cheng HS, Liang J, Wu CC, Shyu YI (2013) Functional recovery of older people with hip fracture: does malnutrition make a difference? J Adv Nurs 69(8):1691-1703

74. Sullivan DH, Nelson CL, Klimberg VS, Bopp MM (2004) Nightly enteral nutrition support of elderly hip fracture patients: a pilot study. J Am Coll Nutr 23(6):683-691

75. Hommel A, Bjorkelund KB, Thorngren KG, Ulander K (2007) Nutritional status among patients with hip fracture in relation to pressure ulcers. Clin Nutr 26(5):589-596

76. Gunnarsson GAK, Lonn K, Gunningberg L (2009) Does nutritional intervention for patients with hip fractures reduce postoperative complications and improve rehabilitation? J Clin Nurs 18(9):1325-33

77. Delmi M, Rapin CH, Bengoa JM, Delmas PD, Vasey H, Bonjour JP (1990) Dietary supplementation in elderly patients with fractured neck of the femur. Lancet 335(8696):1013-1016

78. Tkatch TL, Rapin CH, Rizzoli R, Slosman D, Nydegger V, Vasey $\mathrm{H}$ et al (1992) Benefits of oral protein supplementation in elderly patients with fracture of the proximal femur. J Am Coll Nutr 11(5):519-25

79 Schurch SMA, Rizzoli R, Slosman D, Vadas L, Vergnaud P, Bonjour JP (1998) Protein supplements increase serum insulin-like growth factor-I levels and attenuate proximal femur bone loss in patients with recent hip fracture. A randomized, double-blind, placebo-controlled trial. Ann Intern Med. 128(10):801-9

80 Espaulella J, Guyer H, Diaz-Escriu F, Mellado-Navas JA, Castells M, Pladevall M (2000) Nutritional supplementation of elderly hip fracture patients. A randomized, double-blind, placebo-controlled trial. Age Ageing 29(5):425-31

81. Houwing RH, Rozendaal M, Wouters-Wesseling W, Beulens JW, Buskens E, Haalboom JR (2003) A randomised, double-blind assessment of the effect of nutritional supplementation on the prevention of pressure ulcers in hip-fracture patients. Clin Nutr 22(4):401-405

82. Tidermark J, Ponzer S, Carlsson P, Soderqvist A, Brismar K, Tengstrand B et al (2004) Effects of protein-rich supplementation and nandrolone in lean elderly women with femoral neck fractures. Clin Nutr 23(4):587-596

83. Tengstrand B, Cederholm T, Soderqvist A, Tidermark J (2007) Effects of protein-rich supplementation and nandrolone on bone tissue after a hip fracture. Clin Nutr 26(4):460-465

84. Botella-Carretero JI, Iglesias B, Balsa JA, Arrieta F, Zamarron I, Vazquez C (2010) Perioperative oral nutritional supplements in normally or mildly undernourished geriatric patients submitted to surgery for hip fracture: a randomized clinical trial. Clin Nutr 29(5):574-579

85. Myint MW, Wu J, Wong E, Chan SP, To TS, Chau MW et al (2013) Clinical benefits of oral nutritional supplementation for elderly hip fracture patients: a single blind randomised controlled trial. Age Ageing 42(1):39-45

86. Flodin L, Cederholm T, Saaf M, Samnegard E, Ekstrom W, AlAni AN et al (2015) Effects of protein-rich nutritional supplementation and bisphosphonates on body composition, handgrip strength and health-related quality of life after hip fracture: a 12-month randomized controlled study. BMC Geriatr 15:149
87 Wyers WCE, Reijven PLM, Breedveld-Peters JJL, Denissen KFM, Schotanus MGM, van Dongen M et al (2018) Efficacy of nutritional intervention in elderly after hip fracture: a multicenter randomized controlled trial. J Gerontol A Biol Sci Med Sci. 73(10): 1429-37

88. Niitsu NM, Ichinose D, Hirooka T, Mitsutomi K, Morimoto Y, Sarukawa J et al (2016) Effects of combination of whey protein intake and rehabilitation on muscle strength and daily movements in patients with hip fracture in the early postoperative period. Clin Nutr 35(4):943-9

89. Ekinci EO, Yanik S, TerziogluBebitoglu B, YilmazAkyuz E, Dokuyucu A, Erdem S (2016) Effect of calcium betahydroxy-beta-methylbutyrate (CaHMB), vitamin d, and protein supplementation on postoperative immobilization in malnourished older adult patients with hip fracture: a randomized controlled study. Nutr Clin Pract 31(6):829-35

90. Malafarina MV, Uriz-Otano F, Malafarina C, Martinez JA, Zulet MA (2017) Effectiveness of nutritional supplementation on sarcopenia and recovery in hip fracture patients. A multi-centre randomized trial. Maturitas 101:42-50

91. Invernizzi M, de Sire A, D'Andrea F, Carrera D, Reno F, Migliaccio S et al (2018) Effects of essential amino acid supplementation and rehabilitation on functioning in hip fracture patients: a pilot randomized controlled trial. Aging Clin Exp Res. 31(10):1517-1524

92. Bauer J, Biolo G, Cederholm T, Cesari M, Cruz-Jentoft AJ, Morley JE et al (2013) Evidence-based recommendations for optimal dietary protein intake in older people: a position paper from the PROT-AGE Study Group. J Am Med Dir Assoc 14(8):542-559

93 Chevalley CT, Hoffmeyer P, Bonjour JP, Rizzoli R (2010) Early serum IGF-I response to oral protein supplements in elderly women with a recent hip fracture. Clinical nutrition. 29(1):78-83

94. Liu LM, Yang J, Yu X, Huang X, Vaidya S, Huang F et al (2015) The role of perioperative oral nutritional supplementation in elderly patients after hip surgery. Clin Interv Aging. 10:849-58

95 Avenell A, Smith TO, Curtain JP, Mak JC, Myint PK (2016) Nutritional supplementation for hip fracture aftercare in older people. Cochrane Database Syst Rev. 11:CD001880

96. Rizzoli R, Stevenson JC, Bauer JM, van Loon LJ, Walrand S, Kanis JA et al (2014) The role of dietary protein and vitamin D in maintaining musculoskeletal health in postmenopausal women: a consensus statement from the European Society for Clinical and Economic Aspects of Osteoporosis and Osteoarthritis (ESCEO). Maturitas 79(1):122-132

97. Jensen AL, Lomborg K, Wind G, Langdahl BL (2014) Effectiveness and characteristics of multifaceted osteoporosis group education-a systematic review. Osteoporos Int 25(4):1209-1224

98. Morfeld JC, Vennedey V, Muller D, Pieper D, Stock S (2017) Patient education in osteoporosis prevention: a systematic review focusing on methodological quality of randomised controlled trials. Osteoporos Int 28(6):1779-1803

99. Raybould G, Babatunde O, Evans AL, Jordan JL, Paskins Z (2018) Expressed information needs of patients with osteoporosis and/or fragility fractures: a systematic review. Arch Osteoporos 13(1):55

100. Merle B, Chapurlat R, Vignot E, Thomas T, Haesebaert J, Schott AM (2017) Post-fracture care: do we need to educate patients rather than doctors? The PREVOST randomized controlled trial. Osteoporos Int 28(5):1549-1558

Publisher's note Springer Nature remains neutral with regard to jurisdictional claims in published maps and institutional affiliations. 